$\underline{\xi}=-5$

\title{
Comparative analyses of Nigerian and US corn Stalks, using PY-GC/MS
}

\author{
Anthonia E. Eseyin ${ }^{1}$, El Barbary Hassan ${ }^{1}$, Emad M. El-Giar ${ }^{2}$ \\ ${ }^{1}$ Department of Sustainable Bioproducts, Mississippi State University, USA \\ ${ }^{2}$ School of Sciences, University of Louisiana at Monroe, USA \\ *Corresponding author E-mail: eseyinae@gmail.com
}

\begin{abstract}
Pyrolysis gas chromatography mass spectrometry (Py-GC/MS) studies were carried out on the Nigerian and US corn stalks at $500{ }^{\circ} \mathrm{C}$. Analyses of the fast pyrolysis products showed that the Nigerian corn stalks produced more diverse compounds like: acetaldehyde, acetic acid methyl ester, 2,3-pentanedione, 1-hydroxy-2-butanone, butanedial, phenol and vanillin. On the other hand, the pyrolyzed US corn stalks produced compounds like: furfural, phenol, 2-methoxy, 2-methylbenzaldehyde, and 2-methoxy-4-vinylphenol which had significantly high peak area percentages. Few anhydrous sugars were detected in the pyrolysis products of both samples. Both samples were found to be good biomass for the production of bio-oil and chemicals. However, the Nigerian corn stalks seem to be more suitable for the production of bio-oil while the US corn stalks seem to be more suitable for the production of valuable chemicals
\end{abstract}

Keywords: Bio-Oil; Fast pyrolysis; Nigerian corn stalks; US corn stalks; PY-GC/MS; and Valuable chemicals.

\section{Background}

Recently, a lot of attention has been given to biomass, as a sustainable and renewable alternative energy source that can replace fossil fuels (Heo et al., 2010; Ko et al., 2012; Park et al., 2012). The growing interest in the efficient utilization of renewable resources is because of the problems of environmental pollution, global climate change, and depletion of fossil fuel reserves. Biomass energy has been identified to be one of the most important elements of the sustainable energy system because it is abundant, renewable and has significant environmental benefits. It is estimated that biomass contributes $10-14 \%$ of the global energy supply and about $38 \%$ of the energy supply in the developing countries (Bhattacharya, Salam, \& Sharma, 2000; McKendry, 2002). Biomass has been identified to be the only carbon resource that can produce liquid, solid, and gaseous fuels. Lignocellulosic biomass is the most inexpensive sustainable source of carbon that can be used as feedstock for the production of renewable energy and raw materials (Vispute, Zhang, Sanna, Xiao, \& Huber, 2010). Biomass has been known to compose mainly of cellulose, hemicellulose, and lignin. Cellulose is a high molecular weight (106 or more $\mathrm{g} / \mathrm{mol})$ linear polymer of $\beta$ - $(1 \rightarrow 4)$ linked D-glucose units. Biomass comprises about $40-50 \%$ cellulose. Unlike cellulose, which is a homopolymer carbohydrate, hemicellulose is a heteropolymer of various polymerized monosaccharides such as hexoses (e.g., glucose, galactose, mannose), pentoses (e.g., xylose, arabinose), and uronic acids (e.g., glucuronic acid, 4-O-methyl glucuronic acid, galacturonic acid) (Saha, 2003; R. Sun, Lawther, \& Banks, 1998). Hemicellulose constitutes $20-30 \%$ of biomass and can be easily hydrolyzed by an acid to produce its monomer components. Lignin is a highly complex three dimensional crosslinked macromolecular substance that consists of substituted phenylpropane units (e.g., guaiacyl, syringyl, and p-hydroxy phenyl) linked together by C-O and C-C bonds (Nadji et al., 2009). Many technologies have been used for biomass conversion, including direct combustion, thermochemical, biochemical, and agrochemical processes (Balat \& Balat, 2009; Demirbas, 2009). Out of these technologies, pyrolysis is considered the promising thermochemical conversion route and plays a vital role in biomass conversion to renewable energy. In general, pyrolysis takes place when biomass is heated to high temperatures in the absence of oxygen where an array of products is formed. Biomass pyrolysis is an extremely complex process that involves a series of reactions that depend on many factors (Huang, Wei, Yin, \& Wu, 2012; Karasmanoglu \& Tetik, 1998; Raveendran, Ganesh, \& Khilar, 1995). Fast pyrolysis of biomass can produce approximately 75 $80 \mathrm{wt} \%$ bio-oil, 15-25 wt\% char, and 10-20 wt\% gases (Bahng, Mukarakate, Robichaud, \& Nimlos, 2009).

The research on the conversion of plant materials (e.g., grasses, trees, etc.) to useful energy sources via pyrolysis is continuous and will never stop because pyrolysis is the direct route to liquid transportation fuels and specialty chemicals. Fast pyrolysis of biomass has the potential of reducing the effects of greenhousegas emissions that are generated from fossil fuel combustion. It can also promote energy independence and national security by eliminating the need to import petroleum products for fuels and chemicals. These products are often broadly categorized as volatiles and char (bio-char) (Bahng et al., 2009). The volatile fraction (gas or liquid, depending on its molecular weight) can be used as a fuel or as a chemical feedstock. The solid fraction is also useful in several applications, including domestic fuel, activated carbon, and as reducing agent in metallurgy.

Fast pyrolysis yields a large quantity of bio-oil with a heating value that is approximately half the heating value of fossil fuel. Another advantage of fast pyrolysis is that it has a great potential for fuel and valuable chemicals (Venderbosch \& Heeres, 2011). 
Most of the chemicals in conventional bio-oils are in very low contents, making them difficult to recover and also economically unattractive. However, recently, with the selective control of the biomass pyrolysis, bio-oils that are rich in specific valuable chemicals have been produced. (Branca, Di Blasi, \& Galgano, 2012; Cheng, Jae, Shi, Fan, \& Huber, 2012; Dobele et al., 2005; Lu, Xiong, Li, Guo, \& Zhu, 2009). In addition, during fast pyrolysis of biomass, various phenolic compounds, mainly derived from lignin, are produced. These compounds are useful as phenol replacement, especially in the production of phenolic resins (AmenChen, Pakdel, \& Roy, 1997). Pyrolysis-gas chromatography/mass spectrometry (Py-GC/MS) is a quick, convenient, and powerful technique for the analysis of the pyrolysis products of many organic substances, including complex polymeric materials such as epoxy resins. The technique provides a wealth of chemical information for any given sample.

Many fast pyrolysis studies have been conducted (Ab Rasid \& Asadullah, 2014; Chang et al., 2014; Lorenc-Grabowska \& Rutkowski, 2013; Q. Xie \& Tong, 2014; Y. Xie, Xu, Fang, Luo, \& Ma, 2013). However, none of these studies, to the best of our knowledge, involved a comparative analysis of different types of corn stalks. Therefore, the current study involves comparative analyses of the fast pyrolysis of Nigerian and US corn stalks, using Py-GC/MS. The ultimate goal of this investigation is to determine which of these two corn stalks is suitable for the production of bio-oil and or valuable chemicals.

\section{Methods}

\subsection{Elemental analysis}

Elemental analysis was performed on the Nigerian and US corn stalks using CE 440 elemental analyzer (EAI Analytical, Inc., NH, USA) to identify the carbon, hydrogen, nitrogen, and oxygen contents. Ethylene diamine tetra acetic acid (EDTA) was used as a standard. The method was corrected with a blank. Approximately $0.60 \mathrm{~g}$ of oven-dried sample was wrapped in tin aluminum foil cups and burned for each test. The combustion process occurred at $950{ }^{\circ} \mathrm{C}$ in the combustion chamber with pure oxygen $(99.9 \%$ high purity). Helium was used as carrier gas. All the tests were conducted in triplicate, and the average values of results reported.

\subsection{Preparation of corn stalks}

Nigerian corn stalks were collected from some farms in the city of Jos, Nigeria, while the US corn stalks were collected from the State farm in the city of Starkville, MS, USA. The stalks were oven-dried individually at $120^{\circ} \mathrm{C}$ for 2 hours. The individual corn stalks were then crushed in a Bauer Mill (Bauer Brothers Co. $\mathrm{MN}$, USA) and screened to a particle diameter of 0.5-2 $\mathrm{mm}$, using a universal vibrating screen.

\subsection{Pyrolysis-GC/MS procedure}

$4.0 \mathrm{mg}$ of each ground sample of the Nigerian and US corn stalks was individually placed in a quartz capillary tube. Each tube was then placed in in a CDS pyroprobe (500 series, model 5150). The pyroprobe was interfaced with a $300{ }^{\circ} \mathrm{C}$ transfer line, into a platinum coil attachment. Each sample was pyrolyzed at $500{ }^{\circ} \mathrm{C}$ at 20 ${ }^{\circ} \mathrm{C} / \mathrm{ms}$ heating rate. The hold time at the pyrolysis temperature was approximately $10 \mathrm{~s}$. The pyrolysis vapors were directly transferred to the GC/MS (Model: Clarus 500 GC/MS, Perkin Elmer, Inc., MA, USA) which carried out the analysis. The transfer line and injector temperatures were kept at $300{ }^{\circ} \mathrm{C}$. An Elite-35MS capillary column $(30 \mathrm{~m} \times 0.25 \mathrm{~mm} \times 0.25 \mu \mathrm{m})$ was used for chromatographic separation. Helium (99.9\%) was the carrier gas with a constant flow rate of $1 \mathrm{~mL} / \mathrm{min}$ and a split ratio of 1:8. During the analysis of the pyrolytic products from the stalks, the GC oven was heated from $40{ }^{\circ} \mathrm{C}$ to $280{ }^{\circ} \mathrm{C}$ ( $2 \mathrm{~min}$ ) with the heating rate of $10^{\circ} \mathrm{C} / \mathrm{min}$. The $\mathrm{GC} / \mathrm{MS}$ interface was held at $280{ }^{\circ} \mathrm{C}$, and the mass spectrometer was operated in EI mode at $70 \mathrm{eV}$.

\subsection{Product analysis}

The peak area and peak area $\%$ of each pyrolytic product were identified and determined. Each experiment was repeated at least three times under the same conditions, and the average values of the peak area percentages were calculated and used for discussion. The chromatographic peaks were discriminated and analyzed by means of the NIST MS library and other literature data (Artigues, Puy, Bartroli, \& Fabregas, 2014; Samanya, Hornung, Apfelbacher, \& Vale, 2012; J.-P. Sun, Sui, Zhang, Tan, \& Wang, 2013; Zhang et al., 2013; Zhang et al., 2009). For each chemical composition, a calibrated peak area \% was identified to represent its relative content. Besides, it was known that the products could not be collected during the Py-GC/MS experiments, and therefore, the yields of total organic pyrolysis products could not be determined. The total calibrated chromatographic peak areas were used to reveal the changes of product yields, because the mass of feedstock was kept exactly the same during each experiment. However, some peaks were not identified.

\section{Results and discussions}

\subsection{Proximate and ultimate analyses}

The results of the proximate and ultimate analyses of the Nigerian and US corn stalks are shown in Table 1 . The moisture content of the two samples was $0.0 \%$ because the samples were previously oven-dried. However, the ash content, HHV, and carbon content values were higher for the Nigerian corn stalks. On the other hand, the $\%$ for volatiles, fixed carbon, hydrogen, nitrogen, and oxygen are higher for the US corn stalks. The value for the sulfur content is the same for both samples.

Table 1: The Main Characteristics of Dry Nigerian and US Corn Stalks.

\begin{tabular}{lcc}
\hline Characteristics & Nigerian corn stalks & US corn stalks \\
\hline Ultimate Analysis (\%) & & \\
Carbon & 60.30 & 56.29 \\
Hydrogen & 5.51 & 5.96 \\
Nitrogen & 0.85 & 0.96 \\
Sulfur & 0.10 & 0.10 \\
Oxygen* & 33.24 & 36.69 \\
Proximate Analysis (\%) & & \\
Moisture & 0.00 & 0.00 \\
Ash & 6.89 & 4.75 \\
Volatile & 76.14 & 77.71 \\
Fixed carbon & 16.97 & 17.54 \\
HHV (BTU/lb) & 8153 & 7957 \\
\hline
\end{tabular}

*By difference

\subsection{GC/MS of pyrolyzed Nigerian and US corn stalks at $500{ }^{\circ} \mathrm{C}$}

Figs. 1 and 2 show the GC/MS chromatograms of the pyrolyzed Nigerian and US corn stalks. The two figures look similar with only slight differences.

\subsection{Comparative study of the Py-GC/MS results of the Nigerian and US corn stalks, based on the compounds detected}

The pyrolyzed corn stalks produced several compounds that were derived from the cleavage of their individual components (cellulose, hemicellulose, and lignin). The compounds detected in this research are similar to those detected in corn Stover pyrolysis studies previously conducted. Table 2 is a list of compounds detected in the Py-GC/MS analysis of the Nigerian and US corn stalks. 
Many compounds with varying peak area percentages were identified in both samples. However, acetaldehyde, acetic acid, methyl ester, 2,3-pentanedione, 1-hydroxy-2-butanone, butanedial, 2,5furandione,dihydro-3-methylene-, phenol, phenol-3-ethoxy-, 1,2benzenediol,3-methoxy-, phenol,4-ethyl-2-methoxy-, and vanillin, were detected in the pyrolyzed Nigerian corn stalks but absent in the pyrolyzed US corn stalks, while 1,2-ethanediol,monoacetate, propanoic acid, 2-oxo-,methyl ester, 2(5H)-furanone, 2furancarboxaldehyde, 5-methyl benzaldehyde,2-methyl-, were detected in the pyrolyzed US corn stalks but were absent in the pyrolyzed Nigerian corn stalks.

It is interesting to notice that more diverse compounds were identified in the pyrolyzed Nigerian corn stalks while fewer diverse compounds were identified in the pyrolyzed US corn stalks. Interestingly, the compounds that were identified in the pyrolyzed US corn stalks had relatively larger peak area percentages.

\subsection{Comparative Py-GC/MS of the Nigerian and US corn stalks, based on the relative peak area\% of the classified compounds}

The compounds detected in the Py-GC/MS analysis of the Nigerian and US corn stalks were classified into acids, esters, aldehydes, ketones, furans, phenolic compounds, levoglucosan, and other compounds. The average of the peak area percentages of the compounds detected are presented in Fig. 3. The phenolic compounds had the largest peak area percentages with the pyrolyzed US corn stalks producing more of this group of compounds. These phenolic compounds, mainly derived from lignin, are valuable replacement for phenol in the production of phenolic resins (Amen-Chen et al., 1997).

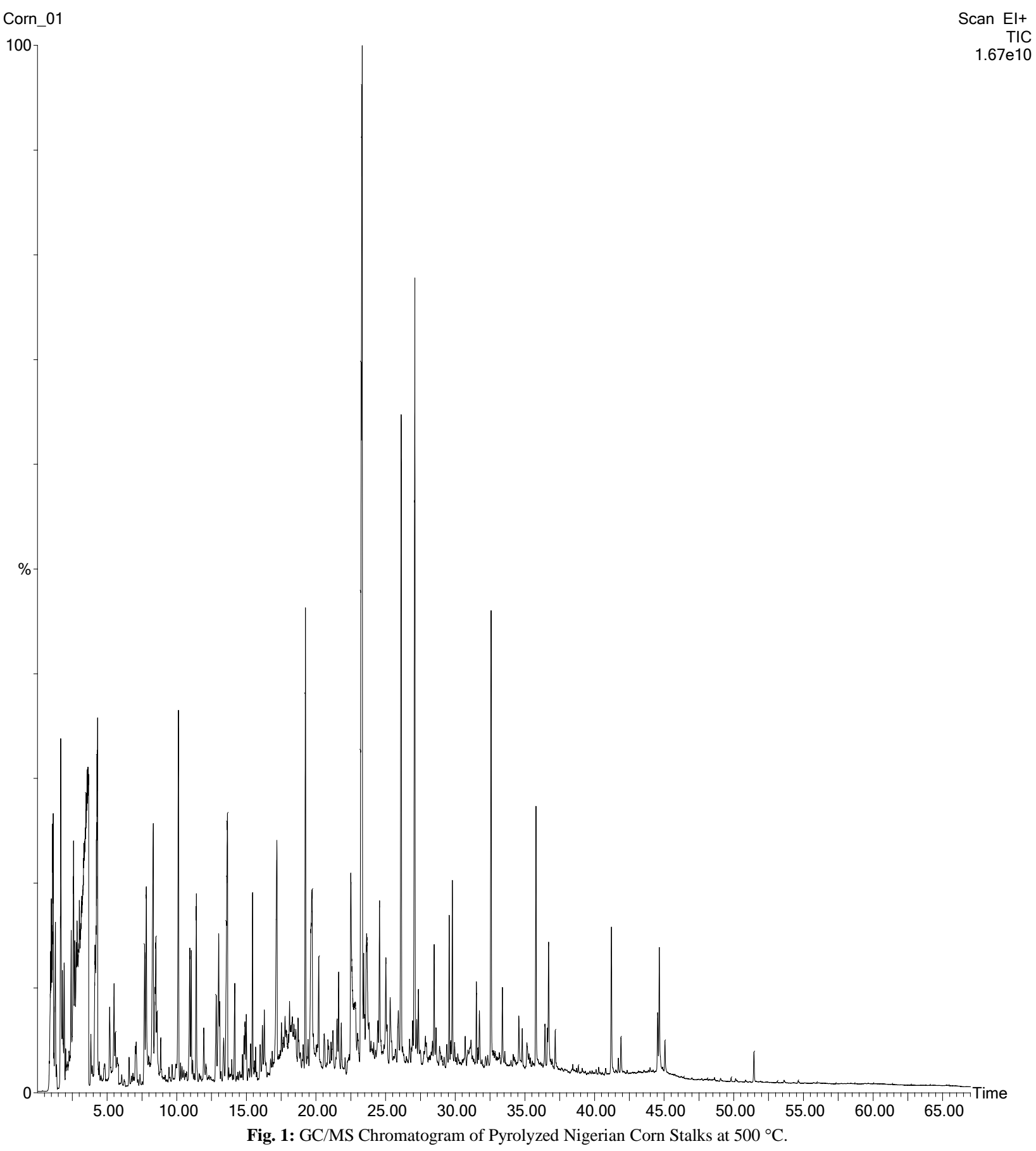




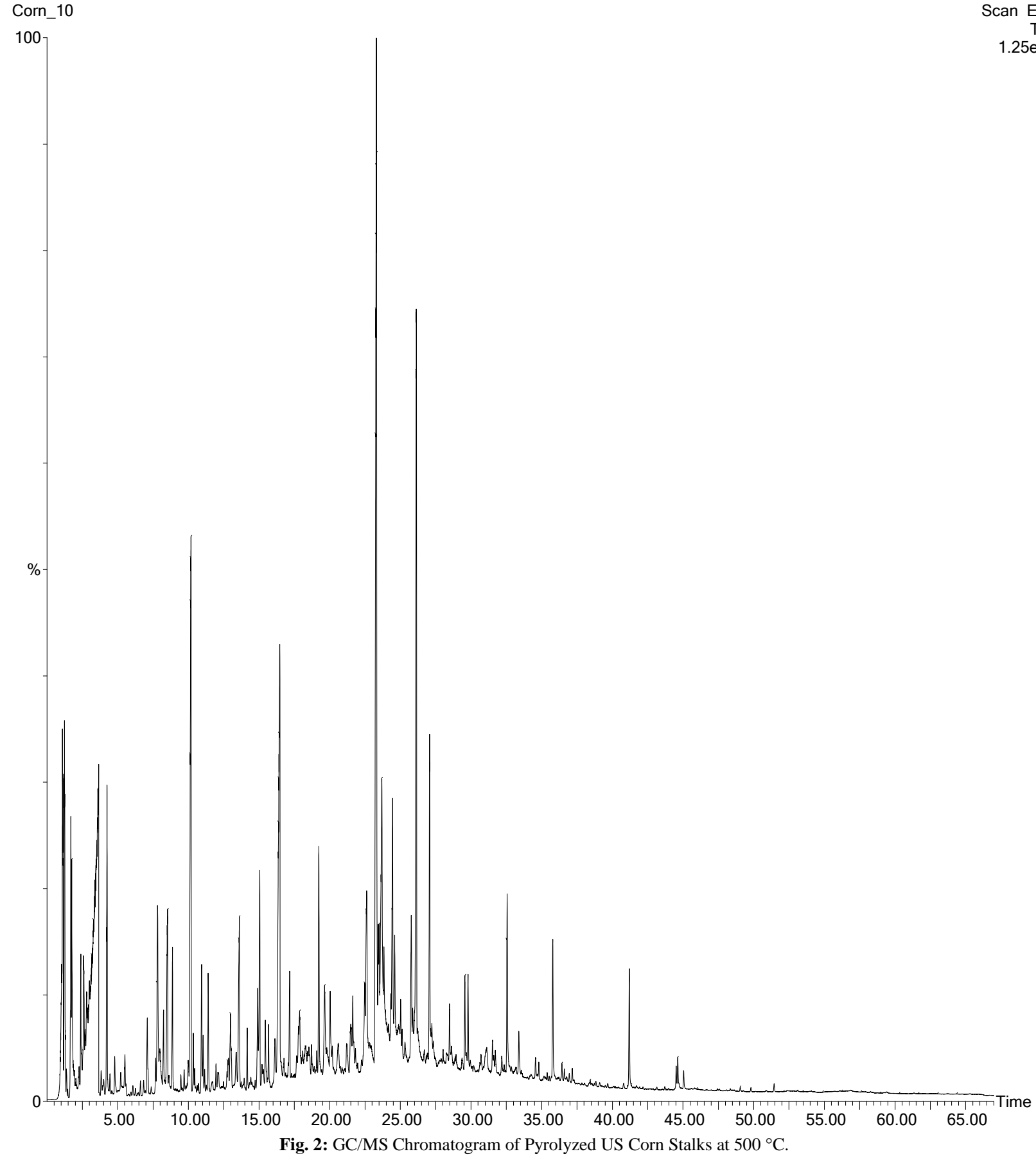


Table 2: Compounds detected in the Py-GC/MS of the Nigerian and US corn stalks

\begin{tabular}{|c|c|c|c|}
\hline \multirow{2}{*}{ Retention Time (min) } & \multirow{2}{*}{ Compound Name } & \multicolumn{2}{|c|}{ Peak Area $(\%)$} \\
\hline & & $\begin{array}{c}\text { Nigerian } \\
\text { Corn Stalks }\end{array}$ & $\begin{array}{c}\text { American } \\
\text { Corn Stalks }\end{array}$ \\
\hline 1.28 & Acetaldehyde & 0.74 & - \\
\hline 1.68 & 1-Propen-2-ol, acetate & 1.46 & 1.55 \\
\hline 1.91 & Acetic acid, methyl ester & 0.40 & - \\
\hline 2.41 & Hydroxyl acetaldehyde & 0.42 & 0.53 \\
\hline 2.58 & 2,3-Butanedione & 0.77 & 0.59 \\
\hline 3.62 & Acetic acid & 12.33 & 11.36 \\
\hline 4.31 & 2-Propanone, 1-hydroxy- & 3.78 & 1.70 \\
\hline 5.17 & 2,3-Pentanedione & 0.41 & - \\
\hline 7.68 & 1-Hydroxy-2-butanone & 0.56 & - \\
\hline 7.81 & 1,2-Ethanediol, mono acetate & - & 1.58 \\
\hline 8.31 & Butanediol & 1.66 & - \\
\hline 8.52 & Propanoic acid, 2-oxo-, methyl ester & - & 1.24 \\
\hline 10.11 & Furfural & 2.20 & 4.56 \\
\hline 10.93 & 2-Furanmethanol & 0.57 & 0.66 \\
\hline 11.40 & 2-Propanone1-acetyloxy- & 0.94 & 0.61 \\
\hline 12.97 & 2-(5H)-Furanone & - & 0.70 \\
\hline 13.63 & 1,2-Cyclopentanedione & 2.14 & 1.30 \\
\hline 14.16 & 2,5-Furandione, dihydro-3-methylene- & 0.50 & - \\
\hline 14.90 & 2-Furancarboxaldehyde,5-methyl- & - & 0.59 \\
\hline 15.44 & Phenol & 0.83 & - \\
\hline 17.18 & 1,2-Cyclopentanedione,3-methyl- & 1.83 & 0.64 \\
\hline 19.23 & Phenol, 2-methoxy- & 2.04 & 13.26 \\
\hline 22.49 & Phenol-3-ethoxy- & 3.27 & - \\
\hline 23.29 & 2-Methyl, benzaldehyde, & - & 8.72 \\
\hline 23.63 & 2-Furancarboxaldehyde,5-(hydroxymethyl)- & 1.21 & - \\
\hline 24.44 & Levoglucosan & 0.92 & 1.01 \\
\hline 24.55 & 1,2-Benzenediol, 3-methoxy- & 0.82 & - \\
\hline 25.01 & Phenol, 4-ethyl-2-methoxy- & 0.65 & - \\
\hline 26.11 & 2-Methoxy-4-vinylphenol & 3.66 & 4.58 \\
\hline 27.09 & Phenol, 2,6-dimethoxy & 4.03 & 2.05 \\
\hline 28.47 & Vanillin & 0.58 & - \\
\hline 35.79 & Phenol, 2,6-dimethoxy-4-(2-propenyl)- & 1.33 & 0.95 \\
\hline 41.21 & Hexadecanoic acid & 0.86 & 0.82 \\
\hline 44.64 & Oleic acid & 0.55 & 0.45 \\
\hline
\end{tabular}




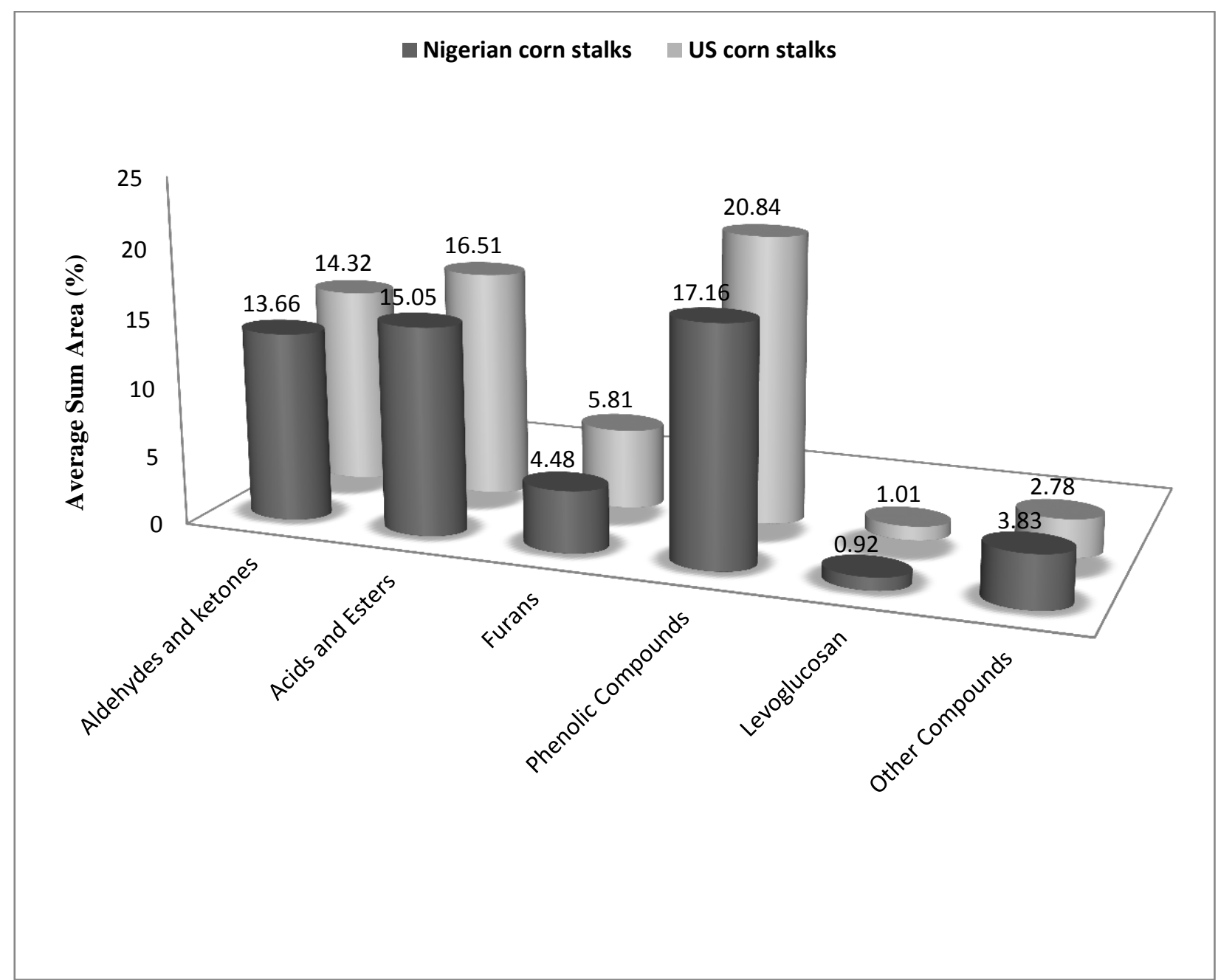

Fig. 3: Histogram Comparing the Py-GC/MS Results of the Nigerian and US Corn Stalks Based on the Relative Average Peak Area \% of the Classified Compounds.

Another group of compounds that was detected in the Py-GC/MS with relatively high area percentages in both the Nigerian and US corn stalks samples are acids and esters. As in the case of the phenolic compounds, the pyrolyzed US corn stalks produced more acids and esters than the Nigerian sample. Aldehydes and ketones were produced in a relatively high quantity by both pyrolyzed samples, with the US sample producing more of this classes of compounds as well. Furans were produced in smaller quantities in both cases with the pyrolyzed US corn stalks producing more furans.

Levoglucosan and other compound were produced in the least quantities. However, the pyrolyzed Nigerian corn stalks produced a higher quantity of other compounds than the pyrolyzed US corn stalks while the pyrolyzed US corn stalks produced a slightly higher quantity of levoglucosan. Acids and ketones are majorly formed from hemicellulose because of its characteristic structure, while furans and small-molecule aldehydes are produced by cellulose. Furfural is considered to have originated from hemicellulose by the concerted cleavage of the bond between oxygen and C-5 position on the xylose unit, followed by ring reforming between C-2 and C-5 position, by dehydration (Lv et al., 2013; Peng \& $\mathrm{Wu}, 2010)$. Small molecular weight aldehydes originate mainly from the secondary decomposition of anhydrous sugars because, under high temperatures, the anhydrous sugars (especially levoglucosan) that are generated from the direct conversion of the cellulose molecules can be further decomposed through possible dehydration, fission, decarbonylation, and decarboxylation reactions (Lv et al., 2013; Peng \& Wu, 2010).

The production of aldehydes through the decomposition of anhydrous sugars was confirmed by the fact that very few anhydrous sugars are produced from the fast pyrolysis of cellulose at $500{ }^{\circ} \mathrm{C}$.
In this experiment, a very small quantity of levoglucosan was formed in both pyrolyzed samples. Ketones with slightly large molecular weights are formed mainly from the decomposition of sugar units and then recombination of the opened bonds (Shen \& $\mathrm{Gu}, 2009)$.

Monomeric phenols and cyclic compounds are formed from the fracture of ether linkages and the $\mathrm{C}-\mathrm{C}$ bonds contained in the side chains of lignin monomer. 2-Methoxy-4-vinylphenol and phenol,2,6-dimethoxy are formed from guaiacyl and syringyl lignin units respectively (Hosoya, Kawamoto, \& Saka, 2009).

\section{Conclusion}

The pyrolysis of the Nigerian and US corn stalks produced several compounds that were derived from the cleavage of their individual components (cellulose, hemicellulose, and lignin). The compounds detected in this research are similar to those detected in previously reported corn Stover pyrolysis studies. Very few anhydrous sugars were formed in the fast pyrolysis of both the Nigerian and US corn stalks. Many compounds with varying peak area percentages were identified in both samples. The pyrolyzed Nigerian corn stalks produced more diverse compounds (acetaldehyde, acetic acid, methyl ester, 2,3-pentanedione, 1-hydroxy-2butanone, butanedial, 2,5-furandione,dihydro-3-methylene-, phenol, phenol-3-ethoxy-, and vanillin) than the pyrolyzed US corn stalks which produced (furfural, phenol,2-methoxy-, 2-methyl, benzaldehyde, and 2-methoxy-4-vinylphenol). In general, the compounds produced from the US samples showed significantly higher peak area percentages than the Nigerian samples. Both samples are good biomass for the production of bio-oil and valua- 
ble chemicals. However, the Nigerian corn stalks seem to be a better biomass for the production of bio-oil as it produced more diverse compounds while the US corn stalks seem to be a better biomass for the production of valuable chemicals because the compounds identified in this sample were formed in a higher quantity.

\section{References}

[1] Ab Rasid, N. S., \& Asadullah, M. (2014). Recent development of biomass fast pyrolysis technology and bio-oil upgrading: an overview. Adv. Mater. Res. (Durnten-Zurich, Switz.), 906, 142-147, 147 pp. doi: 10.4028/www.scientific.net/AMR.906.142 http://dx.doi.org/10.4028/www.scientific.net/AMR.906.142.

[2] Amen-Chen, C., Pakdel, H., \& Roy, C. (1997). Separation of phenols from eucalyptus wood tar. Biomass Bioenergy, 13, 25-37. doi 10.1016/s0961-9534(97)00021-4 http://dx.doi.org/10.1016/S0961 9534(97)00021-4.

[3] Artigues, A., Puy, N., Bartroli, J., \& Fabregas, E. (2014). Comparative assessment of internal standards for quantitative analysis of bio-oil compounds by gas chromatography/mass spectrometry using statistical criteria. Energy Fuels, 28, 3908-3915. doi: 10.1021/ef5005545 http://dx.doi.org/10.1021/ef5005545.

[4] Bahng, M.-K., Mukarakate, C., Robichaud, D. J., \& Nimlos, M. R. (2009). Current technologies for analysis of biomass thermochemical processing: A review. Anal. Chim. Acta, 651, 117-138. doi 10.1016/j.aca.2009.08.016 http://dx.doi.org/10.1016/j.aca.2009.08.016.

[5] Balat, M., \& Balat, H. (2009). Recent trends in global production and utilization of bio-ethanol fuel. Appl. Energy, 86, 2273-2282. doi: 10.1016/j.apenergy.2009.03.015 http://dx.doi.org/10.1016/j.apenergy.2009.03.015.

[6] Bhattacharya, S. C., Salam, P. A., \& Sharma, M. (2000). Emissions from biomass energy use in some selected Asian countries. Energy (Oxford), 25, 169-188. doi: 10.1016/s0360-5442(99)00065-1 http://dx.doi.org/10.1016/S0360-5442(99)00065-1.

[7] Branca, C., Di Blasi, C., \& Galgano, A. (2012). Catalyst Screening for the Production of Furfural from Corncob Pyrolysis. Energy Fuels, 26, $1520-1530$ doi: http://dx.doi.org/10.1021/ef202038n.

[8] Chang, J., Wang, W., Ren, X., Li, L., Zhang, Z., Yu, Y., \& Geng, J. (2014). CN103980929A

[9] Cheng, Y.-T., Jae, J., Shi, J., Fan, W., \& Huber, G. W. (2012). Production of Renewable Aromatic Compounds by Catalytic Fast Pyrolysis of Lignocellulosic Biomass with Bifunctional Ga/ZSM-5 Catalysts. Angew. Chem., Int. Ed., 51, 1387-1390, S1387/1381-S1387/1310. doi 10.1002/anie.201107390 http://dx.doi.org/10.1002/anie.201107390.

[10]Demirbas, A. (2009). Biorefineries: Current activities and future developments. Energy Convers. Manage, 50, 2782-2801. doi: 10.1016/j.enconman.2009.06.035 http://dx.doi.org/10.1016/j.enconman.2009.06.035.

[11] Dobele, G., Rossinskaja, G., Dizhbite, T., Telysheva, G., Meier, D., \& Faix, O. (2005). Application of catalysts for obtaining 1, 6anhydrosaccharides from cellulose and wood by fast pyrolysis. J. Anal. Appl. Pyrolysis, 74, 401-405. doi: 10.1016/j.jaap.2004.11.031 http://dx.doi.org/10.1016/j.jaap.2004.11.031.

[12]Heo, H. S., Park, H. J., Dong, J.-I., Park, S. H., Kim, S., Suh, D. J., Park, Y.-K. (2010). Fast pyrolysis of rice husk under different reaction conditions. J. Ind. Eng. Chem. (Amsterdam, Neth.), 16, 27-31. doi: 10.1016/j.jiec.2010.01.026 http://dx.doi.org/10.1016/j.jiec.2010.01.026

[13] Hosoya, T., Kawamoto, H., \& Saka, S. (2009). Role of methoxyl group in char formation from lignin-related compounds. J. Anal. Appl. Pyrolysis, 84, 79-83. doi: 10.1016/j.jaap.2008.10.024 http://dx.doi.org/10.1016/j.jaap.2008.10.024.

[14]Huang, Y., Wei, Z., Yin, X., \& Wu, C. (2012). Pyrolytic characteristics of biomass acid hydrolysis residue rich in lignin. Bioresour. Tech nol., 103, 470-476. doi: 10.1016/j.biortech.2011.10.027 http://dx.doi.org/10.1016/j.biortech.2011.10.027.

[15] Karasmanoglu, F., \& Tetik, E. (1998). Fuel properties of pyrolytic oil of the straw and stalk of rape plant. Renewable Energy, 16, 1090-1093. http://dx.doi.org/10.1016/S0960-1481(98)00422-4.

[16]Ko, C. H., Park, S. H., Jeon, J.-K., Suh, D. J., Jeong, K.-E., \& Park, Y.-K. (2012). Upgrading of biofuel by the catalytic deoxygenation of biomass. Korean J. Chem. Eng., 29, 1657-1665. doi: 10.1007/s11814012-0199-5 http://dx.doi.org/10.1007/s11814-012-0199-5.

[17]Lorenc-Grabowska, E., \& Rutkowski, P. (2013). Activated carbons from solid residue from fast pyrolysis of biomass. Inz. Ochr. Srodowiska, 16, 205-215.
[18]Lu, Q., Xiong, W.-M., Li, W.-Z., Guo, Q.-X., \& Zhu, X.-F. (2009). Catalytic pyrolysis of cellulose with sulfated metal oxides: A promising method for obtaining high yield of light furan compounds. Bioresour. Technol., 100, 4871-4876. doi: 10.1016/j.biortech.2009.04.068 http://dx.doi.org/10.1016/i.biortech.2009.04.068.

[19]Lv, G., Wu, S., Yang, G., Chen, J., Liu, Y., \& Kong, F. (2013). Comparative study of pyrolysis behaviors of corn stalk and its three components. J. Anal. Appl. Pyrolysis, 104, 185-193. doi: 10.1016/j.jaap.2013.08.005 http://dx.doi.org/10.1016/j.jaap.2013.08.005

[20] McKendry, P. (2002). Energy production from biomass (part 1): overview of biomass. Bioresour. Technol., 83, 37-46. doi: 10.1016/s09608524(01)00118-3 http://dx.doi.org/10.1016/S0960-8524(01)00118-3.

[21]Nadji, H., Diouf, P. N., Benaboura, A., Bedard, Y., Riedl, B., \& Stevanovic, T. (2009). Comparative study of lignins isolated from Alfa grass (Stipa tenacissima L.). Bioresour. Technol., 100, 3585-3592. doi: 10.1016/j.biortech.2009.01.074 http://dx.doi.org/10.1016/i.biortech.2009.01.074

[22] Park, H. J., Park, K.-H., Jeon, J.-K., Kim, J., Ryoo, R., Jeong, K.-E., Park, Y.-K. (2012). Production of phenolics and aromatics by pyrolysis of miscanthus. Fuel, 97, 379-384. doi: 10.1016/j.fuel.2012.01.075 http://dx.doi.org/10.1016/j.fuel.2012.01.075.

[23]Peng, Y., \& Wu, S. (2010). The structural and thermal characteristics of wheat straw hemicellulose. J. Anal. Appl. Pyrolysis, 88, 134-139. doi: http://dx.doi.org/10.1016/i.jaap.2010.03.006.

$0.1016 /$ j.jaap. 2010.03 .006

[24] Raveendran, K., Ganesh, A., \& Khilar, K. C. (1995). Influence of mineral matter on biomass pyrolysis characteristics. Fuel, 74, 18121822 doi: $10.1016 / 0016-2361(95) 80013-8$ http://dx.doi.org/10.1016/0016-2361(95)80013-8.

[25] Saha, B. C. (2003). Hemicellulose bioconversion. J. Ind. Microbiol. Biotechnol, 30, 279-291. doi: 10.1007/s10295-003-0049-x http://dx.doi.org/10.1007/s10295-003-0049-x.

[26] Samanya, J., Hornung, A., Apfelbacher, A., \& Vale, P. (2012). Characteristics of the upper phase of bio-oil obtained from co-pyrolysis of sewage sludge with wood, rapeseed and straw. J. Anal. Appl. Pyrolysis, $\quad 94, \quad 120-125 . \quad$ doi: $10.1016 /$ j.jaap.2011.11.017 http://dx.doi.org/10.1016/j.jaap.2011.11.017.

[27] Shen, D. K., \& Gu, S. (2009). The mechanism for thermal decomposition of cellulose and its main products. Bioresour. Technol., 100, 6496-6504. doi: 10.1016/j.biortech.2009.06.095 http://dx.doi.org/10.1016/j.biortech.2009.06.095

[28]Sun, J.-P., Sui, S.-J., Zhang, Z.-J., Tan, S., \& Wang, Q.-W. (2013) Study on the pyrolytic behavior of wood-plastic composites using PyGC/MS. BioResources, 8, 6196-6210, 6115 pp. doi: 10.15376/biores.8.4.6196-6210 http://dx.doi.org/10.15376/biores.8.4.6196-6210

[29]Sun, R., Lawther, J. M., \& Banks, W. B. (1998). Isolation and characterization of hemicellulose $\mathrm{B}$ and cellulose from pressure refined wheat straw. Ind. Crops Prod., 7, 121-128. doi: 10.1016/s09266690(97)00040-x http://dx.doi.org/10.1016/S0926-6690(97)00040-X.

[30] Venderbosch, R. H., \& Heeres, H. J. (2011). Pyrolysis oil stabilization by catalytic hydrotreatment.

[31] Vispute, T. P., Zhang, H., Sanna, A., Xiao, R., \& Huber, G. W. (2010) Renewable chemical commodity feedstocks from integrated catalytic processing of pyrolysis oils. Science (Washington, DC, U. S.), 330, 1222-1227. doi: $10.1126 /$ science. 1194218 http://dx.doi.org/10.1126/science.1194218.

[32]Xie, Q., \& Tong, Z. (2014). CN103833542A.

[33]Xie, Y., Xu, C., Fang, D., Luo, Q., \& Ma, J. (2013). A review on biomass fast pyrolysis oil properties and applications. Adv. Mater. Res (Durnten-Zurich, Switz.), 779-780, 1431-1436, 1437 pp. doi: 10.4028/www.scientific.net/AMR.779-780.1431 http://dx.doi.org/10.4028/www.scientific.net/AMR.779-780.1431.

[34]Zhang, H., Xiao, R., Jin, B., Shen, D., Chen, R., \& Xiao, G. (2013). Catalytic fast pyrolysis of straw biomass in an internally interconnected fluidized bed to produce aromatics and olefins: Effect of different catalysts. Bioresour. Technol., 137, 82-87. doi: 10.1016/j.biortech.2013.03.031 http://dx.doi.org/10.1016/j.biortech.2013.03.031

[35]Zhang, H., Xiao, R., Wang, D., Zhong, Z., Song, M., Pan, Q., \& He, G. (2009). Catalytic Fast Pyrolysis of Biomass in a Fluidized Bed with Fresh and Spent Fluidized Catalytic Cracking (FCC) Catalysts. Energy Fuels, 23, 6199-6206. doi: 10.1021/ef $900720 \mathrm{~m}$ http://dx.doi.org/10.1021/ef900720m. 